\title{
Impact of Ultra Wide Band Emission on Next Generation Weather RADAR and the Downlink of UMTS2600
}

\author{
Bazil Taha Ahmed ${ }^{1}$ and Miguel Calvo Ramon ${ }^{2}$ \\ 1 Universidad Autonoma de Madrid, \\ 2Universidad Politecnica de Madrid \\ Spain
}

\section{Introduction}

The Federal Communications Commission (FCC) agreed in February 2002 to allocate 7.5 $\mathrm{GHz}$ of spectrum for unlicensed use of ultra-wideband (UWB) devices for communication applications in the $3.1-10.6 \mathrm{GHz}$ frequency band, the move represented a victory in a long hard-fought battle that dated back decades. With its origins in the 1960s, when it was called time-domain electromagnetic, UWB came to be known for the operation of sending and receiving extremely short bursts of RF energy. With its outstanding ability for applications that require precision distance or positioning measurements, as well as high-speed wireless connectivity, the largest spectrum allocation ever granted by the FCC is unique because it overlaps other services in the same frequency of operation. Previous spectrum allocations for unlicensed use, such as the Unlicensed National Information Infrastructure (UNII) band have opened up bandwidth dedicated to unlicensed devices based on the assumption that "operation is subject to the following two conditions:

1. This device may not cause harmful interference. Harmful interference is defined as interference that seriously degrades, obstructs or repeatedly interrupts a radio communication service.

2. This device must accept any interference received, including interference that may cause undesired operation. This means that devices using unlicensed spectrum must be designed to coexist in an uncontrolled environment.

Devices utilizing UWB spectrum operate according to similar rules, but they are subject to more stringent requirements because UWB spectrum underlays other existing licensed and unlicensed spectrum allocations. In order to optimize spectrum use and reduce interference to existing services, the FCC's regulations are very conservative and require very low emitted power.

UWB has a number of advantages which make it attractive for consumer communications applications. In particular, UWB systems

- Have potentially low complexity and low cost;

- Have noise-like signal characteristics;

- $\quad$ Are resistant to severe multipath and jamming;

- Have very good time domain resolution. 
In 1988, the NEXRAD Agencies established the WSR-88D (Weather Surveillance Radar 88 Doppler) Radar Operations Centre (ROC) in Norman, Oklahoma. The ROC employees come from the National Weather Service, Air Force, Navy, FAA, and support contractors. The ROC provides centralized meteorological, software, maintenance, and engineering support for all WSR-88D systems. WSR-88D systems will be modified and enhanced during their operational life to meet changing requirements, technology advances, and improved understanding of the application of these systems to real-time weather operations. The ROC also operates WSR-88D test systems for the development of hardware and software upgrades to enhance maintenance, operation, and provide new functionality.

NEXRAD is used to warn the people of the United States about dangerous weather and its location. Meteorologists can now warn the public to take shelter with more notice than any previous radar. There are 158 operational NEXRAD radar systems deployed throughout the United States and at selected overseas locations. The maximum range of the NEXRAD radar is 250 nautical miles. The NEXRAD network provides significant improvements in severe weather and flash flood warnings, air traffic safety, flow control for air traffic, resource protection at military bases, and management of water, agriculture, forest, and snow removal.

The spectrum for UMTS lies between $1900 \mathrm{MHz}$ to $2025 \mathrm{MHz}$ and $2110 \mathrm{MHz}$ to $2200 \mathrm{MHz}$. For the satellite service an own sub-band in the UMTS spectrum is reserved (uplink 1980 $\mathrm{MHz}$ to $2010 \mathrm{MHz}$, downlink $2170 \mathrm{MHz}$ to $2200 \mathrm{MHz}$ ). The remaining spectrum for terrestrial use is divided between two modes of operation. In the FDD (Frequency Division Duplex) mode there are two equal bands for the uplink (1920 MHz to $1980 \mathrm{MHz}$ ) and for the downlink (2110 MHz to $2170 \mathrm{MHz}$ ). In the operation mode TDD (Time division duplex) uplink and downlink are not divided by use of different frequency carriers but by using different timeslots on the same carrier. So there is no need for a symmetrical spectrum but the remaining unpaired spectrum can be used.

The European Conference of Postal and Telecommunications administrations (CEPT) have recommended that the $2500-2690 \mathrm{MHz}$ band should be reserved for the use by licensed UMTS services. It has been recommended that the 2500-2570 and 2620-2690 MHz bands should be paired for UMTS FDD deployment with frequency blocks in multiples of $5 \mathrm{MHz}$. Here after we will dominate this system by UMTS2600.

In (Hamalainen et al., 2002) the coexistence of the UWB system with GSM900, UMTS/WCDMA, and GPS has been investigated. They have evaluated the level of the interference caused by different UWB signal to the three up mentioned systems. Also they have evaluated the performance degradation of UWB systems in the presence of narrow bandwidth interference and pulsed jamming. They have given the bit error rate (BER) of the above mentioned systems for different pulse length.

In (Hamalainen et al., 2004) the coexistence of the UWB system with IEEE802.11a and UMTS in Modified Saleh-Valenzuela Channel has been studied. The UWB system performance has been studied in the presence of multiband interference. The interference sources considered are IEEE802.11a and UMTS which are operating simultaneously with their maximum system bandwidths. The system under consideration is single band and single user UWB link operating at data rate of $100 \mathrm{Mbps}$ without error correction coding. They have given the bit error rate (BER) of the UWB system for different types of modulation (Direct sequence and Time Hopping).

The interference between the UMTS and the UWB system has been studied in (Giuliano et al, 2003). The free space propagation model has been used to calculate the UWB signal propagation loss. It has been concluded that, a carrier frequency of $3.5 \mathrm{GHz}$ is the minimum 
allowable value for UWB device transmitting at $100 \mathrm{Mbps}$ in order to avoid harmful interference between UMTS and UWB. In (Hamalainen et al., 2001a), the effect of the in band interference power caused by different kinds of UWB signal at UMTS/WCDMA uplink and downlink frequency bands has been investigated. UWB frequency spectra have been produced by using several types of narrow pulse waveforms. They have concluded that one can reduce interfering UWB power by using different waveforms and pulse widths to avoid UMTS frequencies without any additional filtering. In (Hamalainen et al., $2001 \mathrm{~b}$ ) the effect of the in band interference power caused by three different kinds of UWB signal on GPS L1 and GSM-900 uplink band has been studied. UWB frequency spectra have been generated by using several types of narrow pulse waveforms based on Gaussian pulse. In band interference power has been calculated over the IF bandwidth of the two victim receiver as a function of the UWB pulse width. Also the signal attenuation with distance has been presented.

In (Ahmed et al., 2004), the effect of the UWB on the DCS-1800 and GSM-900 macrocell downlink absolute range using the (Line of Sight) propagation model between the UWB transmitter and the mobile receiver has been studied without taking into account the shadowing factor within the propagation loss model.

In (ITU, 2003), the effect of UWB system on fixed service system (point to point and Fixed Wireless Access (FWA) systems in bands from 1 to $6 \mathrm{GHz}$ has been investigated. It has been concluded that, when the UWB transmitter is in LOS with the two systems antennas, the effect is very high when the UWB power density is $-41.3 \mathrm{dBm} / \mathrm{MHz}$.

\section{UWB effect on the NEXRAD}

RADAR systems performance (detection) is almost the optimum when the Signal to Noise Ratio (SNR) is $16 \mathrm{~dB}$ or more. Any extra interference due to communications systems degrades the performance (probability of detection with constant range or the range with constant probability of detection) of the radar system. Thus, the extra interference should not exceed a given value. In practice, extra interference should be within the following range:

$$
I_{\text {extra }} \leq 0.1 P_{n-R A D A R}
$$

where

$\mathrm{I}_{\text {extra }}$ is the extra interference due to other communications systems,

$\mathrm{P}_{\mathrm{n}-\mathrm{RADAR}}$ is the RADAR receiver noise calculated as:

$$
P_{n-R A D A R}(d B)=-114+10 \log _{10}\left(B W_{M H Z}\right)+N F(d B)
$$

where

- $\quad \mathrm{BW}_{\mathrm{MHz}}$ is the radar system IF bandwidth measured by $\mathrm{MHz}$.

- $\mathrm{NF}(\mathrm{dB})$ is the RADAR receiver noise figure measured in $\mathrm{dB}$.

The UWB interference power $\mathrm{I}_{\mathrm{UWB}}$ is calculated by:

$$
I_{U W B}=P_{U W B}-L_{U W B}(d)+L_{\text {exra }}+G_{A n t}
$$

where

- $P_{\mathrm{UWB}}$ is the UWB EIRP in $\mathrm{dBm}$ in the radar band, 
- $\quad \mathrm{L}_{\mathrm{UWB}}(\mathrm{d})$ is the propagation loss between the UWB device and the RADAR system as a function of the distance between the UWB source and the radar,

- $\mathrm{L}_{\text {extra }}$ is the extra propagation loss due to tree or building insertion loss when is applicable,

- $\mathrm{G}_{\mathrm{Ant}}$ is the RADAR antenna gain in the direction of the UWB transmitter.

- $\alpha$ is the second propagation exponent of the UWB signal with a typical value of 4 to 5 depending on the surrounding environment.

Using the Two-Slope Propagation Model, the UWB signal propagation loss LuwB in $\mathrm{dB}$ at a distance $d$ can be given as (Ciccoganini et al., 2005):

$$
L_{U W B}(d) \approx \begin{cases}20 \log _{10}\left(\frac{4 \pi d}{\lambda}\right) & d \leq R_{b} \\ 20 \log _{10}\left(\frac{4 \pi R_{b}}{\lambda}\right)+10 \alpha \log _{10}\left(\frac{d}{R_{b}}\right) & R_{b}<d\end{cases}
$$

where $\lambda$ is the wavelength and $R_{b}$ is the break point distance given by (Ahmed et al., 2002):

$$
R_{b}=\frac{4 h_{U W B} h_{R A D A R}}{\lambda}
$$

where

- $h_{U W B}$ is the UWB antenna height,

- $\mathrm{h}_{\text {RADAR }}$ is the RADAR antenna height.

\section{UWB effect on the UMTS2600 downlink performance}

To account for UWB interference, an extra source of interference is added linearly to the

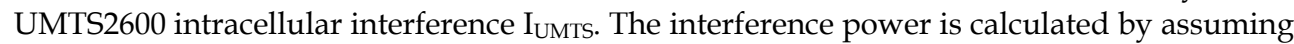
the UWB source to be at different distances from the UMTS2600 receiver (the mobile station). Therefore, the interference power generated by a device UWB, $\mathrm{I}_{\mathrm{UWB}}$, is given by (in dBm) (Ahmed, Ramon, 2008):

$$
I_{U W B}=P_{U W B}-L_{U W B}(d)+G_{U M T S}
$$

where

- $\quad$ PUwB is the UWB EIRP in $\mathrm{dBm}$ in the UMTS2600 band.

- $\mathrm{LuwB}_{\mathrm{u}}(\mathrm{d})$ is the path-loss between the UWB device and the UMTS2600 receiver which varies with the separation distance, $\mathrm{d}$ in $\mathrm{m}$, and

- $\mathrm{G}_{\mathrm{UMTS}}$ is the UMTS2600 antenna gain.

Given that UWB devices are typically low power, short range devices, then the line-of-sight path-loss model is often most appropriate for distances less than $5 \mathrm{~m}$. Thus the UWB signal propagation loss in $\mathrm{dB}$ is calculated as (Ahmed, Ramon, 2008):

$$
L_{U W B}(d) \approx 20 \log _{10}\left(\frac{4 \pi}{\lambda}\right)+20 \log _{10}(d)=40.92+20 \log _{10}(d)
$$

where $\lambda$ is the wavelength at an operating frequency of $2.655 \mathrm{GHz}$. 
The effect of the UWB interference is to reduce the UMTS2600 macrocell range or/and the macrocell capacity.

The macrocell downlink range $\mathrm{R}_{\mathrm{UMTS}}$ with the existence of the UWB interference is given as (Ahmed, Ramon, 2008):

$$
R_{\text {UMTS }}=R_{\text {UMTS }, o} \sqrt[S]{\frac{I_{\text {UMTS }}}{\left(I_{\text {UMTS }}+I_{U W B}\right)}}
$$

where RUMTS,o is the UMTS2600 downlink range without UWB interference.

The UMTS2600 normalized macrocell range $R_{n}$ is given as:

$$
R_{n}=\frac{R_{\text {UMTS }}}{R_{\text {UMYTS }, o}}=\sqrt[s]{\frac{I_{\text {UMTS }}}{\left(I_{\text {UMTS }}+I_{\text {UWB }}\right)}}
$$

where $\mathrm{s}$ is the UMTS2600 outdoor signal propagation exponent (3.5 to 4.5).

The UMTS2600 normalized downlink capacity $C_{n}$ is given as (Ahmed, Ramon, 2008):

$$
C_{n}=\frac{C_{\text {UMTS }}}{C_{\text {UMTS }, o}}=\left(\frac{I_{\text {UMTS }}}{I_{\text {UMTS }}+I_{U W B}}\right)
$$

where $\mathrm{C}_{\text {UMTS }}$ is the UMTS2600 downlink capacity with the UWB interference, and $\mathrm{C}_{\mathrm{UMTS}, \mathrm{o}}$ is the UMTS2600 downlink capacity without the UWB interference.

\section{Results}

For an outdoor environment (UWB transmitter out side of any building), the FCC maximum permitted UWB EIRP power density for the frequency range 2.7 to $3.0 \mathrm{GHz}$ is $61.3 \mathrm{dBm} / \mathrm{MHz}$ while it is $-51.3 \mathrm{dBm} / \mathrm{MHz}$ for indoor environment (UWB transmitter is within a given building).

We study the effect of the UWB system on the NEXRAD system assuming that the RADAR receiver noise is $-114 \mathrm{dBm}$, its operating frequency is $2.9 \mathrm{GHz}$, the second propagation exponent $\alpha$ is 4 and that its antenna height is $30 \mathrm{~m}$. Here we have assumed that, the UWB maximum allowed interference is $-124 \mathrm{dBm}$ (10 dB protection) which give a rise to about $2.5 \%$ reduction of the NEXRAD range. Fig. 1 shows the NEXRAD vertical pattern.

Fig. 2 shows the acceptable UWB power density for three different UWB antenna heights. It can be noticed that the coordinate distance (minimum distance between the UWB transmitter and the Radar) is almost $0 \mathrm{~km}$ when the UWB antenna height is $3 \mathrm{~m}$. The coordinate distance will be 1.12 and $1.50 \mathrm{~km}$ when the UWB antenna height is 15 and $30 \mathrm{~m}$ respectively. Second and third cases (UWB antenna height of 15 to $30 \mathrm{~m}$ ) should be avoided as far as possible. At an UWB antenna height of $30 \mathrm{~m}$, the UWB interference will be injected to the NEXRAD receiver through the NEXRAD antenna main-lobe. Thus, the UWB effect will be the maximum.

Fig. 3 shows the acceptable UWB power density for three different UWB antenna heights assuming that some trees are between the UWB antenna and the RADAR antenna and that the tree absorption loss is $10 \mathrm{~dB}$. It can be noticed that the coordinate distance is $0 \mathrm{~km}$ when the UWB antenna height is $3 \mathrm{~m}$. The coordinate distance will be 0 and $0.48 \mathrm{~km}$ when the $\mathrm{UWB}$ antenna height is 15 and $30 \mathrm{~m}$ respectively. 
Fig. 4 shows the acceptable UWB power density for three different UWB antenna heights assuming that the UWB transmitter is within a high building and that the wall absorption loss is $10 \mathrm{~dB}$. It can be noticed that the coordinate distance is $0 \mathrm{~km}$ when the UWB antenna height is $3 \mathrm{~m}$. The coordinate distance will be 1.12 and $1.50 \mathrm{~km}$ when the UWB antenna height is 15 and $30 \mathrm{~m}$ respectively.

For the above three mentioned cases, it has been assumed that, the RADAR main beam is in the direction of the UWB transmitter and that the RADAR antenna has a tilt of 0.0 .

Fig. 5 shows the acceptable UWB power density for three different UWB antennas tilting assuming that the UWB antenna height is $3 \mathrm{~m}$. It can be noticed that the coordinate distance is $0 \mathrm{~km}$ when the UWB antenna tilt is $0^{\circ}$. Also, the coordinate distance will be $0 \mathrm{~km}$ when the UWB antenna tilt is $3^{\circ}$ or $6^{\circ}$. Thus, the effect of the UWB is null with any positive RADAR antenna tilt of 3 degrees or more assuming that the UWB antenna height is $3 \mathrm{~m}$.

Fig. 6 shows the acceptable UWB power density for three different UWB antennas tilting assuming that the UWB antenna height is $30 \mathrm{~m}$. It can be noticed that the coordinate distance is $1.5 \mathrm{~km}$ when the UWB antenna tilt is $0^{\circ}$. The coordinate distance will be $0 \mathrm{~km}$ for UWB antenna tilt angle of $3^{\circ}$ and $6^{\circ}$.

The same results are applicable for an operating frequency of $3 \mathrm{GHz}$. For a distance of $100 \mathrm{~m}$ between the UWB transmitter and the Radar, the UWB EIRP power density at $3 \mathrm{GHz}$ should be $-84 \mathrm{dBm} / \mathrm{MHz}$ or lower.

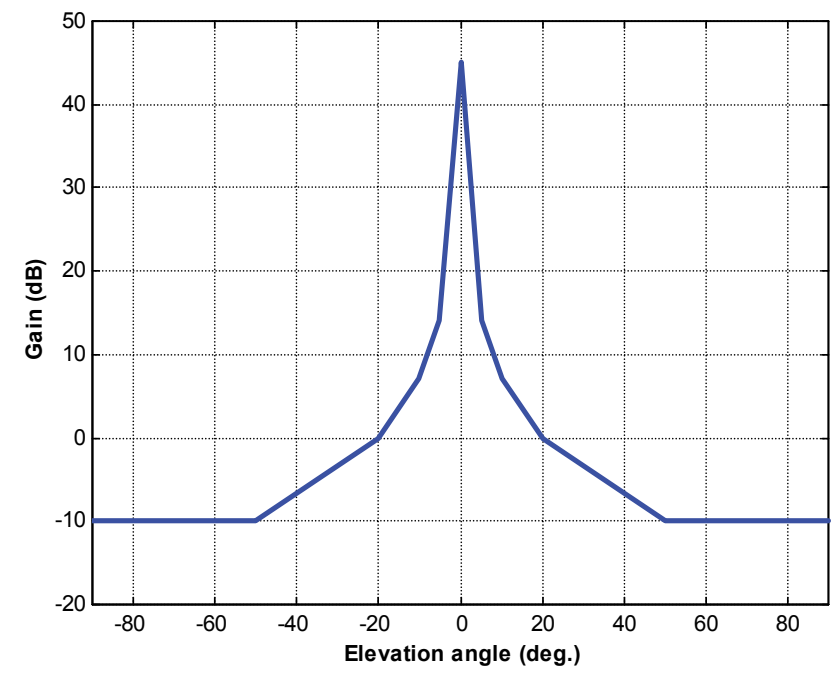

Fig. 1. NEXRAD Vertical Antenna Pattern. 


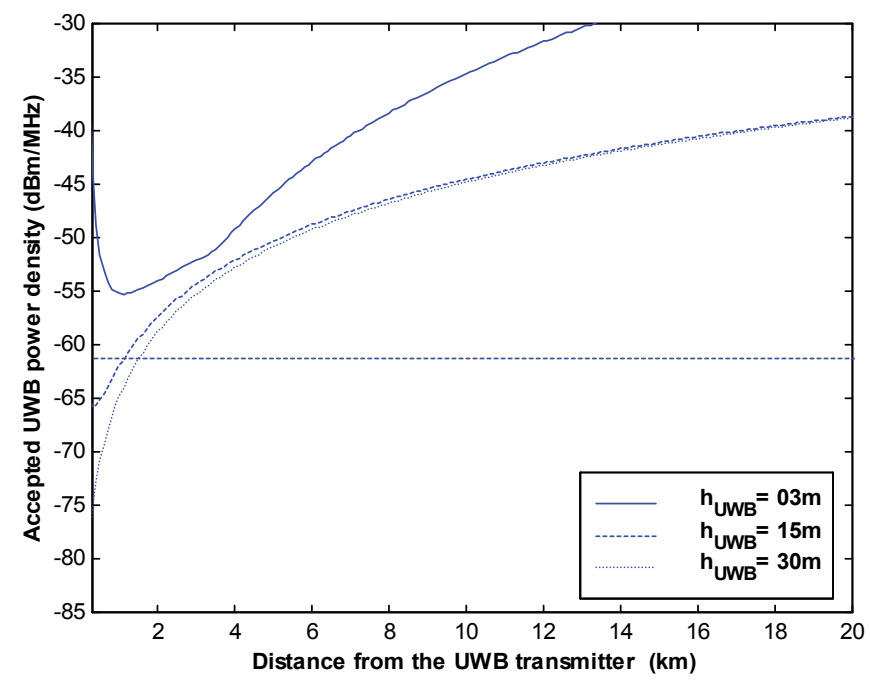

Fig. 2. Maximum permitted UWB EIRP for an outdoor environment for three different UWB antenna height (RADAR antenna height $=30 \mathrm{~m})$.

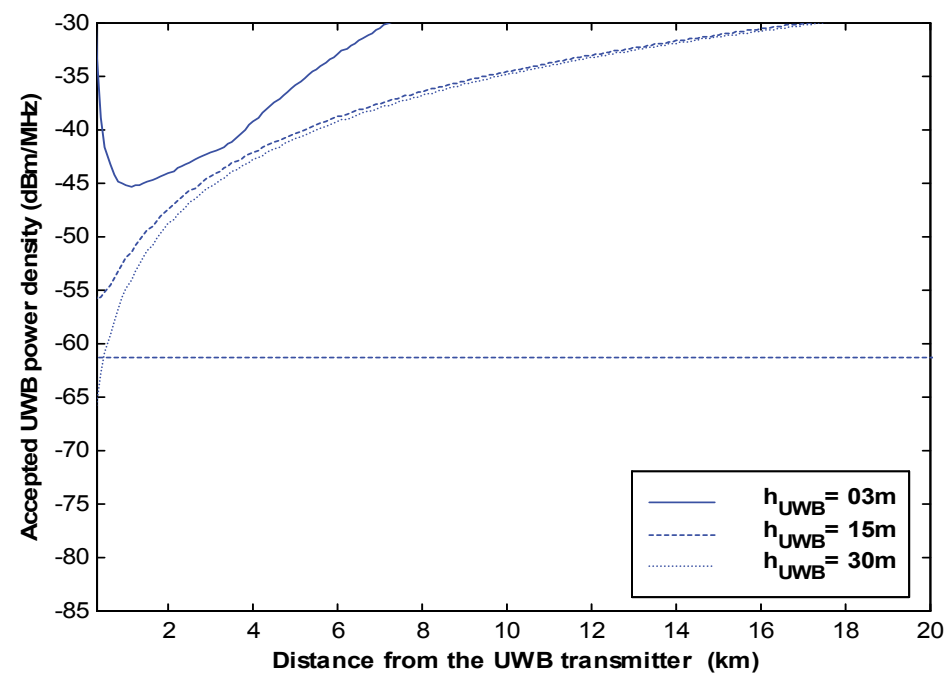

Fig. 3. Maximum permitted UWB EIRP for an outdoor environment for three different UWB antenna height (RADAR antenna height $=30 \mathrm{~m}$ and $10 \mathrm{~dB}$ tree absorption loss). 


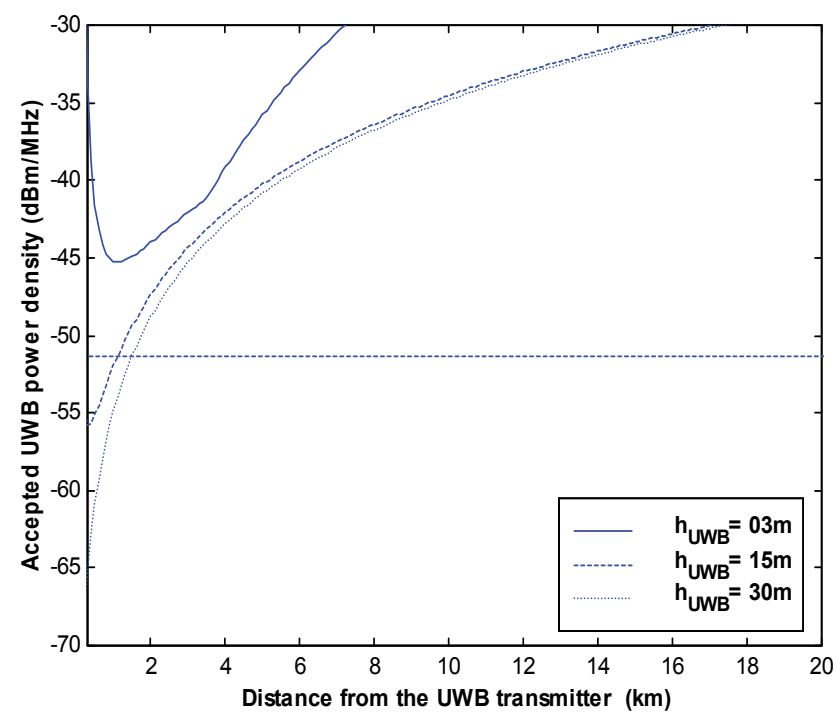

Fig. 4. Maximum permitted UWB EIRP for an indoor environment for three different UWB antenna height (RADAR antenna height $=30 \mathrm{~m}$ and $10 \mathrm{~dB}$ wall absorption loss).

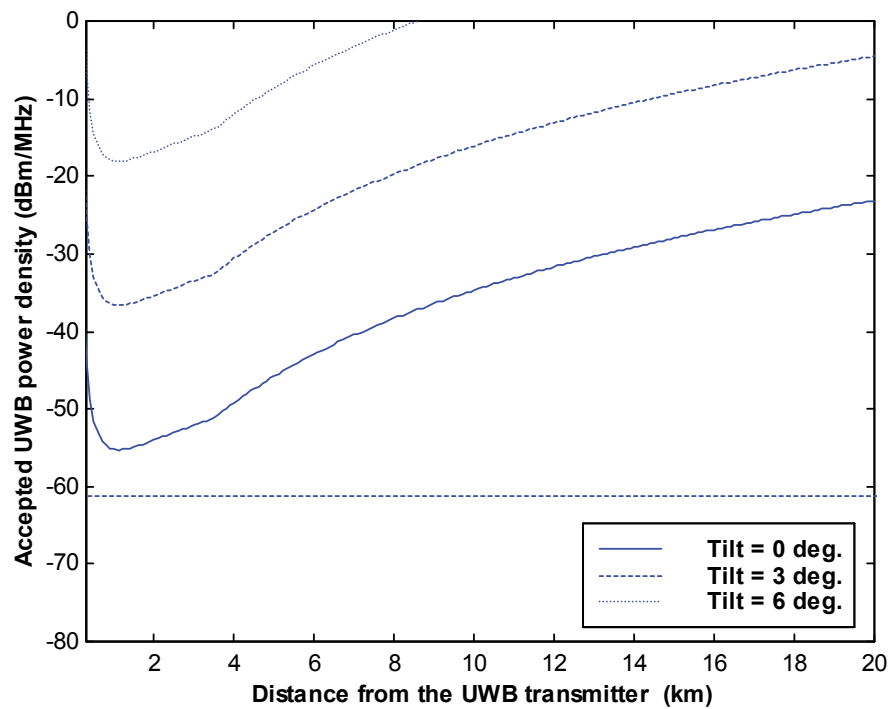

Fig. 5. Maximum permitted UWB EIRP for an outdoor environment for three RADAR antenna tilt (UWB antenna height $=3 \mathrm{~m}$ and RADAR antenna height $=30 \mathrm{~m}$ ). 


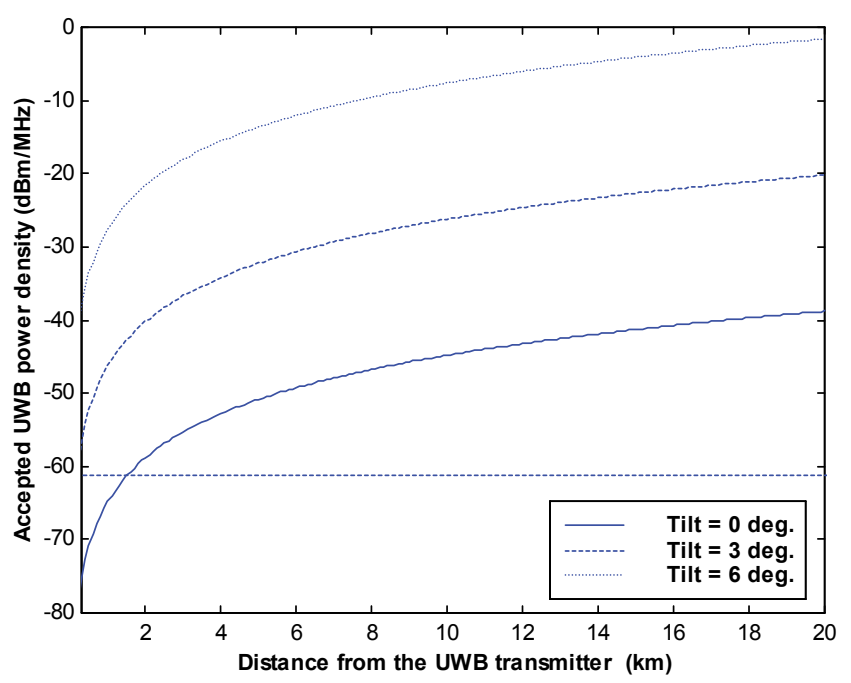

Fig. 6. Maximum permitted UWB EIRP for an outdoor environment for three RADAR antenna tilt (UWB antenna height $=30 \mathrm{~m}$ and RADAR antenna height $=30 \mathrm{~m}$ ).

Here we address the effect of the UWB system on the downlink of the UMTS2600 system. In the analysis we assume that the UWB data rate is higher than the UMTS2600 chip rate, i.e., the UWB bit rate is higher than $4 \mathrm{Mbps}$. In Fig. 7, the UWB interference power on the UMTS2600 downlink (i.e. interference as seen at the mobile) is plotted assuming an average $P_{\text {UwB }}$ of $-51.3 \mathrm{dBm} / \mathrm{MHz}$ within the UMTS2600 bandwidth.

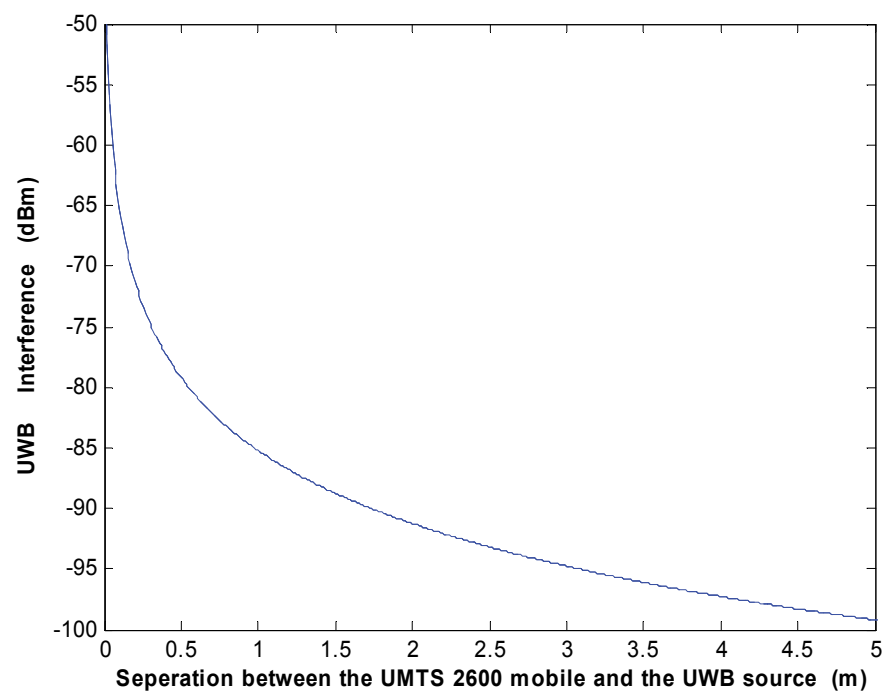

Fig. 7. UWB interference as a function of the separation between the UWB transmitter and the UMTS2600 mobile $\left(\mathrm{P}_{\mathrm{UwB}}=-51.3 \mathrm{dBm} / \mathrm{MHz}\right)$. 
We study the case of voice service $\left(\mathrm{G}_{\mathrm{p}}=25 \mathrm{~dB}\right.$ and $\left.\left(\mathrm{E}_{\mathrm{b}} / \mathrm{N}_{\mathrm{o}}\right)_{\mathrm{req}}=6 \mathrm{~dB}\right)$ (Ahmed, Ramon, 2008) assuming an UMTS2600 interference of $-88 \mathrm{dBm}$ (14 dB noise rise) and UWB power density of $-51.3 \mathrm{dBm} / \mathrm{MHz}$. Fig. 8 shows the downlink macrocell normalized range as a function of the separation between the UMTS2600 mobile and the UWB transmitter for three different values of the propagation exponent s. It can be noticed that the UWB signal creates a high interference which reflects a macrocell normalized range reduction of $26 \%$ when the separation is $1 \mathrm{~m}$. For larger separation, the interference is lower and thus the range reduction is also lower.

Fig. 9 shows the downlink macrocell normalized capacity as a function of the separation between the UMTS2600 mobile and the UWB transmitter for the same UWB power density. It can be noticed that the UWB signal creates a high interference which gives arise a macrocell normalized capacity reduction of $66 \%$ when the separation is $1 \mathrm{~m}$. For larger separation, the interference is lower and thus the normalized capacity reduction is also lower.

Thus, it can concluded that, the UWB recommended power density of $-51.3 \mathrm{dBm}$ recommended by FCC is very high and its effect on the UMTS2600 system is dramatic i.e., a reduction of $26 \%$ of the macrocell range or a reduction of $66 \%$ of the cell capacity. For this reason lower UWB power density should be studied.

Let us now study the case data service $\left(\mathrm{G}_{\mathrm{p}}=14.25 \mathrm{~dB}\right.$ and $\left.\left(\mathrm{E}_{\mathrm{b}} / \mathrm{N}_{\mathrm{o}}\right)_{\text {req }}=4.25 \mathrm{~dB}\right)$ assuming an UMTS2600 total interference of $-92.0 \mathrm{dBm}(10 \mathrm{~dB}$ noise rise and thus highly loaded macrocell). Fig. 10 shows the downlink macrocell normalized range as a function of the UWB power density. It can be noticed that for a distance of $1 \mathrm{~m}$, the macrocell normalized range increases with the reduction of the UWB power density. If we consider that the UWB system is un harmful when the UMTS range reduction is $1 \%$ or less then, the recommended UWB power density should be $-74 \mathrm{dBm} / \mathrm{MHz}$ or lower. This power density is well below the FCC and the ETSI recommendations.

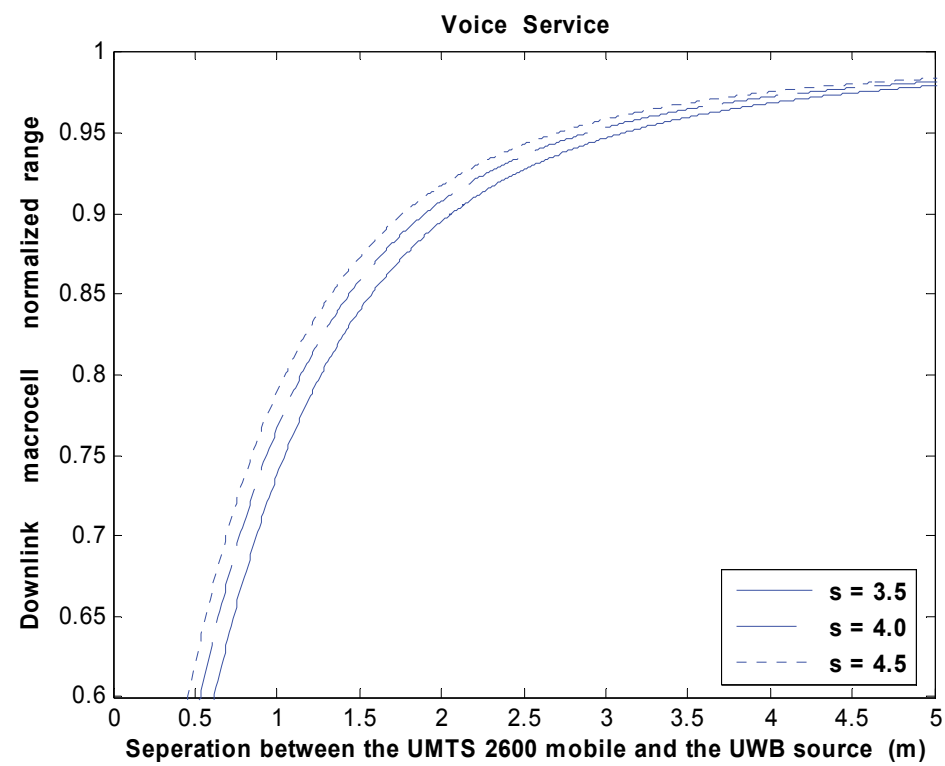

Fig. 8. Effect of the UWB interference on the macrocell range as a function of the separation between the UWB transmitter and the UMTS2600 mobile $\left(\mathrm{P}_{\mathrm{UWB}}=-51.3 \mathrm{dBm} / \mathrm{MHz}\right)$. 


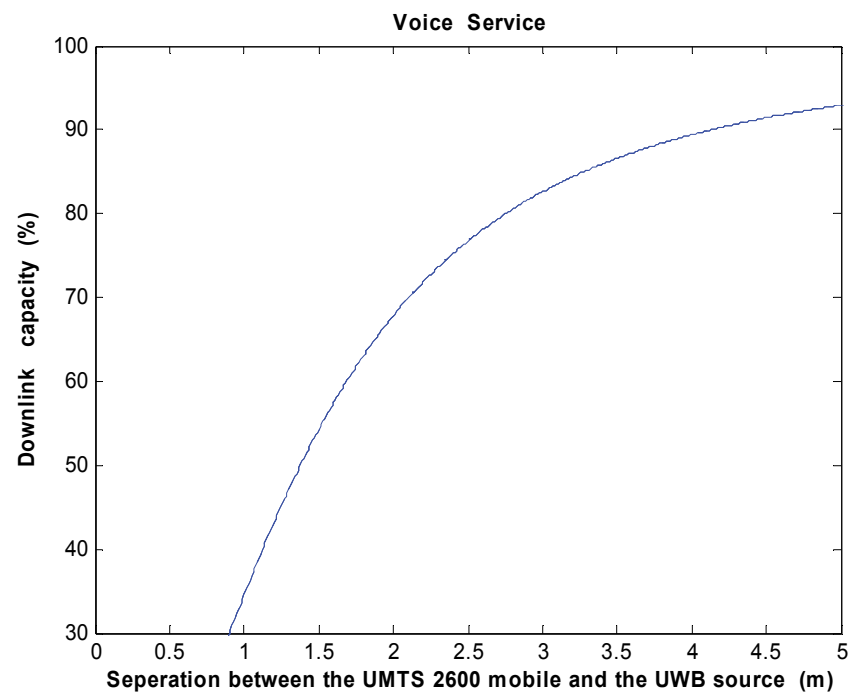

Fig. 9. Effect of the UWB interference on the macrocell normalized capacity as a function of the separation between the UWB transmitter and the UMTS2600 mobile ( $\left.P_{\mathrm{UWB}}=-51.3 \mathrm{dBm} / \mathrm{MHz}\right)$.

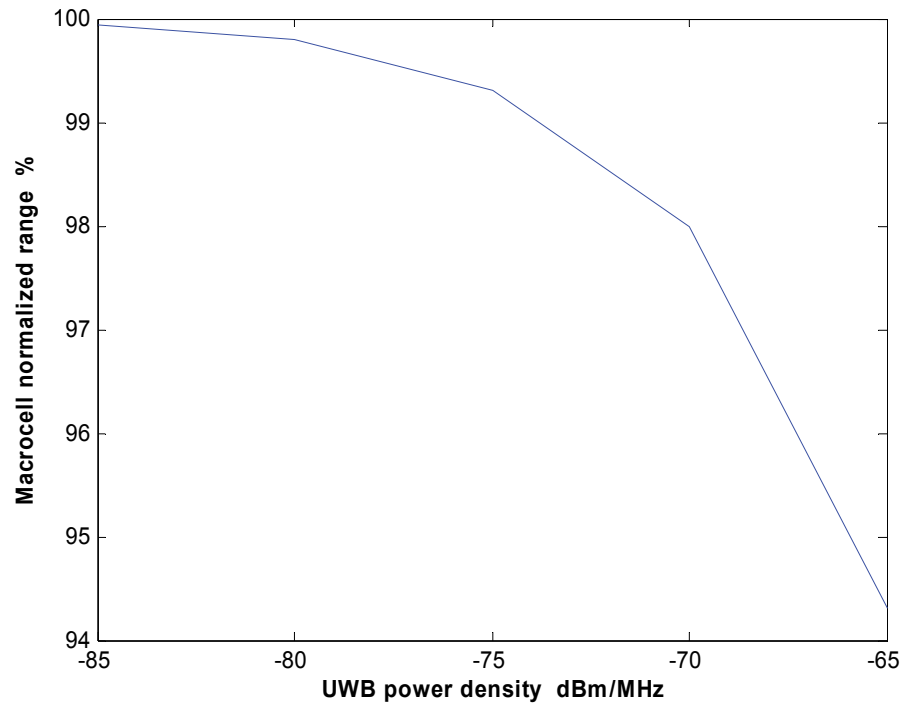

Fig. 10. Effect of the UWB interference on the macrocell normalized range as a function of the UWB power density. 
Fig. 11 shows the downlink macrocell normalized capacity as a function of the UWB power density. It can be noticed that for a distance of $1 \mathrm{~m}$, the macrocell normalized capacity increases with the reduction of the UWB power density. If we consider that the UWB system is un harmful when the UMTS capacity reduction is $1 \%$ or less then, the recommended UWB power density should be $-79 \mathrm{dBm} / \mathrm{MHz}$ or lower. Also, this power density is well below the FCC and the ETSI recommendations.

Then we study the case of multiple UWB transmitters with one UWB transmitter at each $4 \times 4 \mathrm{~m}^{2}$ area of the indoor environment assuming $\mathrm{P}_{\mathrm{UWB}}$ of $-82 \mathrm{dBm} / \mathrm{MHz}, 18 \mathrm{UWB}$ transmitters and noise rise of $10 \mathrm{~dB}$. Fig. 12 shows the downlink macrocell normalized range as a function of the UMTS2600 mobile location for three different values of s. It can be noticed that the UWB signal creates a high interference which will drastically reduce the macrocell normalized range when the UMTS receiver is located at 0 to $0.15 \mathrm{~m}$. At a distance higher than $0.4 \mathrm{~m}$ from the nearest UWB transmitter, the macrocell range reduction is less than $1 \%$.

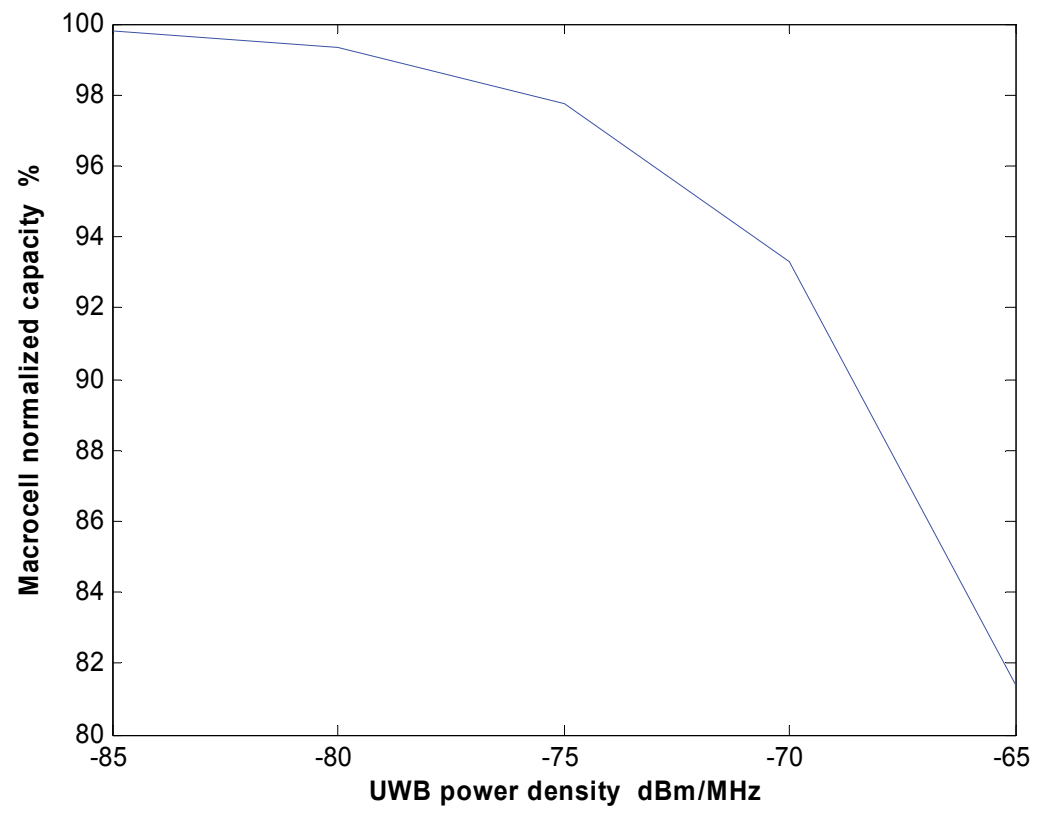

Fig. 11. Effect of the UWB interference on the macrocell normalized capacity as a function the UWB power density. 


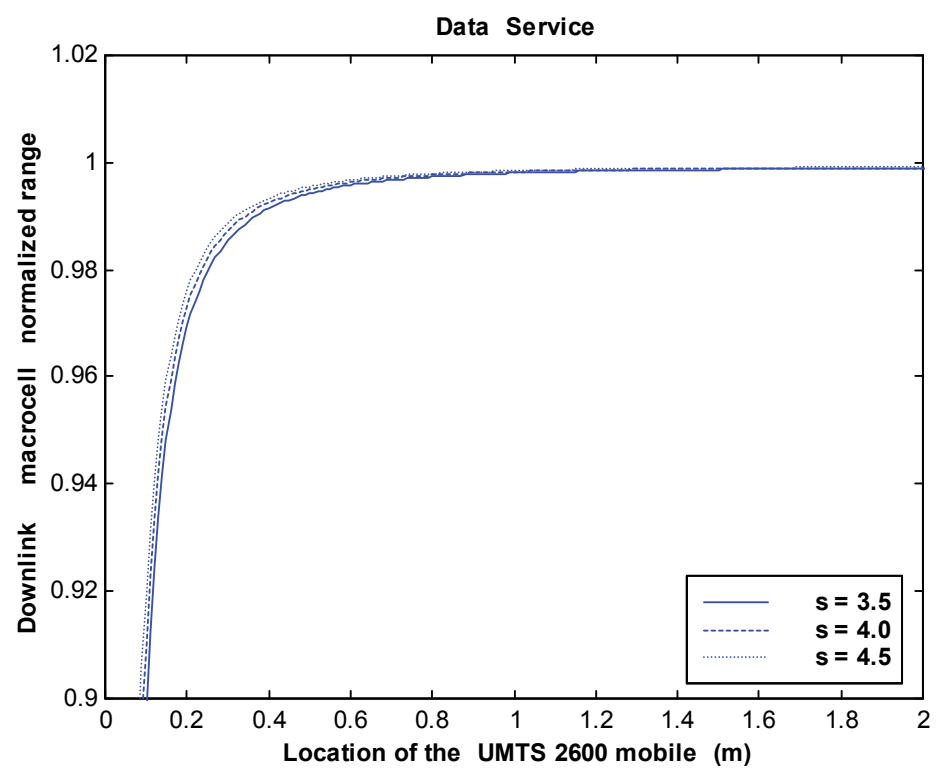

Fig. 12. Effect of the UWB interference on the macrocell range as a function of the UMTS2600 mobile location ( $\mathrm{P}_{\mathrm{UWB}}=-82 \mathrm{dBm} / \mathrm{MHz}$ ) for multi UWB transmitters and $9.5 \mathrm{~dB}$ noise rise.

Fig. 13 shows the downlink macrocell capacity as a function of the UMTS2600 mobile location. It can be noticed that the UWB signal creates a high interference which produces a high macrocell normalized capacity reduction when the UMTS2600 receiver is located at a distance less than $0.2 \mathrm{~m}$ from the nearest UWB transmitter. For a distance greater than $1 \mathrm{~m}$ from the nearest UWB transmitter, the effect of the UWB transmitters is almost null (less than $1 \%$ capacity reduction).

It can be concluded that, for the case of single UWB transmitter, the UMTS2600 can easily tolerate the UWB interference when the UWB EIRP is $-79 \mathrm{dBm} / \mathrm{MHz}$ for a distance between the UWB transmitter and the UMTS mobile of $1 \mathrm{~m}$ or higher. For the case of multi UWB transmitter, the UMTS can easily tolerate the UWB interference when the UWB EIRP is -82 $\mathrm{dBm} / \mathrm{MHz}$. The above mentioned numbers are valid for highly loaded macrocells, i.e., $90 \%$ loaded macrocell. For lower loaded macrocells (50-70)\%, the UMTS2600 system can tolerate (1.2-3) $\mathrm{dB}$ lower UWB power density. If we reduce the critical distance to $0.5 \mathrm{~m}$, we have to lower the maximum accepted UWB power density by $6 \mathrm{~dB}$.

For the common UMTS systems that functions within the band (1.92-2.17) GHz, the tolerable UWB power density is $2 \mathrm{~dB}$ lower than the tolerable UWB power density of UMTS2600, i.e., for single UWB transmitter, the common UMTS system can tolerate UWB power density of $81 \mathrm{dBm} / \mathrm{MHz}$. For multi UWB transmitters, the common UMTS can tolerate UWB power density of $-84 \mathrm{dBm} / \mathrm{MHz}$.

Fig. 14 shows the FCC, ETSI and our recommended UWB power density masks. It can be noticed that, for a frequency lower than $3.1 \mathrm{GHz}$, our recommended mask has always lower accepted UWB power density than the FCC mask. For a frequency of $950 \mathrm{MHz}$ to $3.1 \mathrm{GHz}$, our mask has lower accepted UWB power density than the ETSI mask. 


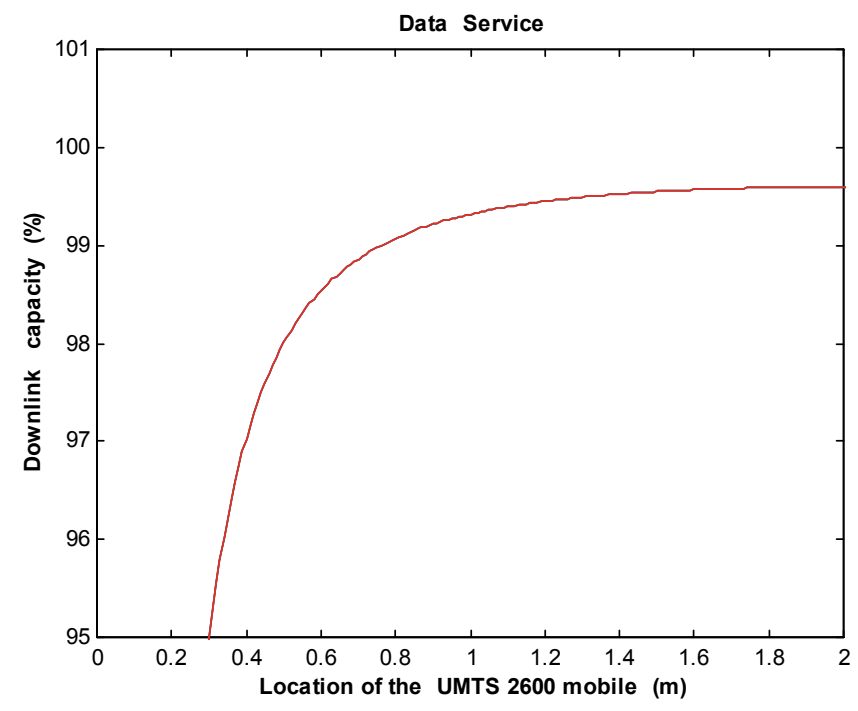

Fig. 13. Effect of the UWB interference on the macrocell normalized capacity as a function of the UMTS2600 mobile location $\left(\mathrm{P}_{\mathrm{UWB}}=-82 \mathrm{dBm} / \mathrm{MHz}\right)$ for multi UWB transmitters and 9.5 $\mathrm{dB}$ noise rise.

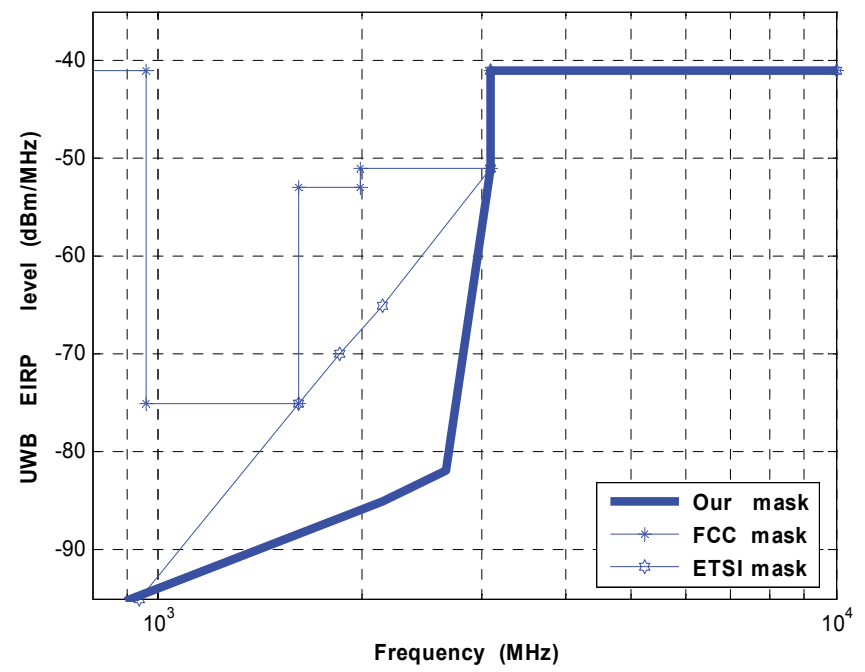

Fig. 14. FCC, ETSI and our recommended accepted UWB power density. 


\section{Conclusions}

The effect of the UWB interference on the on Next Generation Weather RADAR (NEXRAD) has been presented. The coordination distance has been given for different scenarios, i.e., for different UWB antenna heights, different NEXRAD antenna tilt and when a group of trees exist between the UWB antenna and the NEXRAD antenna. Also the case of UWB transmitter in indoor environment has been studied. It has been noticed that, for high antenna tilt of NEXRAD antenna, the effect of the UWB system is null. When the antenna heights of both UWB and NEXRAD are the same the effect of the UWB will be the maximum. Also, it has been noticed that, when a group of trees or a given obstacle exist between the UWB and NEXRAD antennas, the effect of the UWB system will be lower than the case of clear path between the antennas of both systems.

The effect of the UWB transmitters on the UMTS2600 downlink for different configuration and environments has been studied. It has been noticed that, for the case of low UWB power density $(-79 \mathrm{dBm} / \mathrm{MHz})$, the effect of the UWB signals is low when the distance between the UWB transmitter and the UMTS2600 receiver is greater than $1 \mathrm{~m}$. For the case of multi UWB transmitters, the accepted UWB power density is 1 to $5 \mathrm{~dB}$ lower than the accepted UWB power density of the UWB single transmitter case. The UWB power density reduction depends on the number of the UWB transmitters and their spatial density, i.e., the higher is the number of UWB transmitters and their spatial density, higher should be the reduction of the UWB power density. If we reduce the critical distance to $0.5 \mathrm{~m}$, we have to lower the maximum accepted UWB power density by $6 \mathrm{~dB}$. It has been noticed that, the effect of the UMTS2600 signal propagation exponent (s) is very little when it has a value of 3.5 to 4.5 .

\section{References}

Ahmed B. T., Ramon M. C. \& Ariet L. H., 2002," Capacity and Interference Statistics of Highways W-CDMA Cigar-Shaped Microcells (Uplink Analysis), IEEE Communications Letters, Vol. 6, No. 5, pp. 172-174.

Ahmed B. T., Ramon M. C. \& Ariet L. H., 2004, “Impact of Ultra Band (UWB) on Macrocell Downlink of DCS-1800 and GSM-900 Systems", Radioenginnering, Vol. 14, No.1, pp. 51-55.

Ahmed B. T., Ramón M. C.,2008, “On the Impact of Ultra-Wideband (UWB) on Macrocell Downlink of UMTS and CDMA-450 Systems", IEEE Electromagnetic Compatibility, Vol. 5, No. 2, pp. 406-412.

Ciccoganini W., Durantini A., and Cassioli D., 2005, "Time domain propagation measurements of the UWB Indoor Channel Using PN-Sequence in the FCCCompliant Band 3.6-6 GHz", IEEE trans. Antennas and Propagation, Vol. 53, No. 4, pp. 1542-1549.

Giuliano R., Mazzenga F., Vatalaro F., "On the interference between UMTS and UWB systems", pp: 339 - 343, IEEE Conference on Ultra Wideband Systems and Technologies, 2003 , 16-19 Nov. 2003.

Hamalinen M., Hovinen V., Iinatti J., Latva-aho M., 2001: "In band Interference Power Caused by Different Kinds of UWB Signals at UMTS/WCDMA Frequency Bands", , the 2001 IEEE Radio and Wireless Conference, RAWCON 2001, pp. 97-100, Waltham-Boston, Massachusetts, USA, Aug. , 2001. 
Hamalinen M., Iinatti J., Hovinen V., Latva-aho M., 2001," In band Interference of Three Kind of UWB Signals in GPS L1 Band and GSM900 Uplink Band", the 12th International Symposium on Personal, Indoor and Mobile Radio Communications, PIMRC2001, pp. D 76-80, USA, Sep - Oct, 2001.

Hamalainen M. , Hovinrn V. , Tesi R., Iinatti J. \& Latava-aho M., 2002, “ On the UWB System Coexistance with GSM900, UMTS/WCDMA, and GPS", IEEE Journal on Selected Areas in Communications, Vol. 20, No. 9, pp. 1712-1721.

Hamalinen M., Tesi R., Iinatti J.," UWB co-existence with IEEE802.11a and UMTS in modified Saleh-Valenzuela channel", Ultra Wideband Systems, 2004, pp. 45 - 49, May 2004.

Holma H. , Toskala A., 2000, “WCDMA for UMTS”, John Wiley \& Sons.

ITU Document 1-8/29-E, 2003, "Updating of Preleminary Study on Coexistance Betwwen UWB and the Fixed Service in Band from 1 to $6 \mathrm{GHz}$ ". 


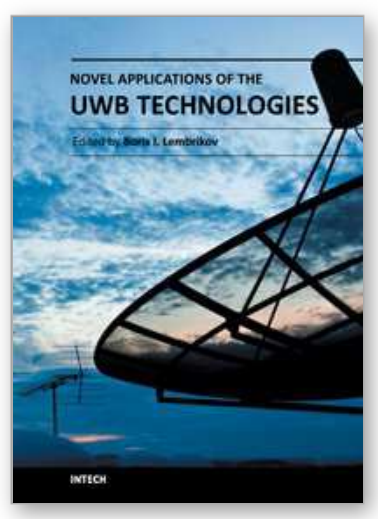

\author{
Novel Applications of the UWB Technologies \\ Edited by Dr. Boris Lembrikov
}

ISBN 978-953-307-324-8

Hard cover, 440 pages

Publisher InTech

Published online 01, August, 2011

Published in print edition August, 2011

Ultra wideband (UWB) communication systems are characterized by high data rates, low cost, multipath immunity, and low power transmission. In 2002, the Federal Communication Commission (FCC) legalized low power UWB emission between $3.1 \mathrm{GHz}$ and $10.6 \mathrm{GHz}$ for indoor communication devices stimulating rapid development of UWB technologies and applications. The proposed book Novel Applications of the UWB Technologies consists of 5 parts and 20 chapters concerning the general problems of UWB communication systems, and novel UWB applications in personal area networks (PANs), medicine, radars and localization systems. The book will be interesting for engineers and researchers occupied in the field of UWB technology.

\title{
How to reference
}

In order to correctly reference this scholarly work, feel free to copy and paste the following:

Bazil Taha Ahmed and Miguel Calvo Ramon (2011). Impact of Ultra Wide Band Emission on Next Generation Weather RADAR and the Downlink of UMTS2600, Novel Applications of the UWB Technologies, Dr. Boris Lembrikov (Ed.), ISBN: 978-953-307-324-8, InTech, Available from: http://www.intechopen.com/books/novelapplications-of-the-uwb-technologies/impact-of-ultra-wide-band-emission-on-next-generation-weather-radarand-the-downlink-of-umts 2600

\section{INTECH}

open science | open minds

\author{
InTech Europe \\ University Campus STeP Ri \\ Slavka Krautzeka 83/A \\ 51000 Rijeka, Croatia \\ Phone: +385 (51) 770447 \\ Fax: +385 (51) 686166 \\ www.intechopen.com
}

\author{
InTech China \\ Unit 405, Office Block, Hotel Equatorial Shanghai \\ No.65, Yan An Road (West), Shanghai, 200040, China \\ 中国上海市延安西路65号上海国际贵都大饭店办公楼405单元 \\ Phone: +86-21-62489820 \\ Fax: $+86-21-62489821$
}


(C) 2011 The Author(s). Licensee IntechOpen. This chapter is distributed under the terms of the Creative Commons Attribution-NonCommercialShareAlike-3.0 License, which permits use, distribution and reproduction for non-commercial purposes, provided the original is properly cited and derivative works building on this content are distributed under the same license. 